\section{Modifying the Interagency Emergency Health Kit to include treatment for non-communicable diseases in natural disasters and complex emergencies: the missing clinical, operational and humanitarian perspectives}

We welcome Tonelli et als ${ }^{1}$ contribution to raising the profile of non-communicable diseases (NCD), especially on NCD medicines in humanitarian emergencies, a topic that to date has received very little attention. ${ }^{2}$ However, we would question the message and conclusion of this paper on three grounds.

First, from a clinical perspective, the inclusion only of mixed insulin for diabetes exacerbations would seem to be a mistake, with rapid acting and NPH being more important. Although we agree with the authors that the benefits of treatment of NCDs 'will take time to accrue' as well as the exclusion of cancer and chronic kidney disease, it would seem to make little sense then to include statins which would be more for long-term prevention of adverse events. ${ }^{1}$ The authors negate an important fact that people with NCDs represent a spectrum of individuals and individual risk for an adverse event. A child with type 1 diabetes is possibly more at risk of an adverse event than a man aged 40 years with a blood pressure of 140/90 mm Hg. That same man's risk profile changes if he smokes, is obese, has already had a myocardial infarction, etc. Also from a methodological perspective, we wonder whether it would have been better to look at numbers needed to treat in order to get a better view of cost implications.

The second point of disagreement with the authors is operational. Focusing only on medicines in scenario 1 negates the additional costs of managing an acute exacerbation of an NCD, such as the need for oxygen during an acute episode of asthma, beds, drips, different human resources, etc. These resources will already be stretched managing the humanitarian emergency and adding acute episodes of NCDs will overburden the system. More and more humanitarian settings are also prolonged emergencies and within these contexts, there is the need for long-term care and guaranteeing a continuum of care as the primary aim of the humanitarian response is to prevent and reduce excess mortality. ${ }^{3}$ Tonelli $e a^{1}{ }^{1}$ rightly state, there is a need to consider the burden of disease in different settings. However, the response is also dependent on whether the emergency is a typhoon or a protracted conflict, the impact this humanitarian emergency has had on existing services and the pre-existing capacity of health system.

Our final element is in terms of equity and what could be referred to the humanitarian view of addressing NCDs. The authors state that proponents of scenario 2 would offer several reasons as to why treatment should be offered. We believe that these arguments should be taken into consideration as they are in line with the Humanitarian Charter which includes the right to life with dignity, the right to protection and security, and the right to receive humanitarian assistance on the basis of need'. ${ }^{3}$ People with NCDs in humanitarian emergencies should receive a solution to their health problem. This may not be a medicine, but to simply not care for a vulnerable subpopulation within a crisis setting is in our opinion unethical and inequitable. ${ }^{4}$

\section{Sigiriya Aebischer Perone, ${ }^{1}$ David Beran ${ }^{2}$}

${ }^{1}$ Division of Tropical and Humanitarian Medicine, Geneva University Hospitals, Geneva, Switzerland

${ }^{2}$ Division of Tropical and Humanitarian Medicine, Geneva University Hospitals and University of Geneva Faculty of Medicine, Geneva, Switzerland

Correspondence to Dr David Beran; david.beran@unige.ch

Competing interests None declared.

Provenance and peer review Not commissioned; internally peer reviewed.

Open Access This is an Open Access article distributed in accordance with the Creative Commons Attribution Non Commercial (CC BY-NC 4.0) license, which permits others to distribute, remix, adapt, build upon this work noncommercially, and license their derivative works on different terms, provided the original work is properly cited and the use is non-commercial. See: http:// creativecommons.org/licenses/by-nc/4.0/

To cite: Aebischer Perone S, Beran D. Modifying the Interagency Emergency Health Kit to include treatment for non-communicable diseases in natural disasters and complex emergencies: the missing clinical, operational and humanitarian perspectives. BMJ Global Health 2017;2:e000287. doi:10.1136/ bmjgh-2017-000287

Received 8 January 2017

Accepted 10 January 2017

BMJ Glob Health 2017;2:e000287. doi:10.1136/bmjgh-2017-000287

\section{REFERENCES}

1. Tonelli M, Wiebe N, Nadler B, et al. Modifying the Interagency Emergency Health Kit to include treatment for non-communicable diseases in natural disasters and complex emergencies. BMJ Global Health 2016;1:e000128.

2. Demaio A, Jamieson J, Horn R, et al. Non-communicable diseases in emergencies: a call to action. PLoS Curr 2013;5.

3. The Sphere Project. Humanitarian Charter and Minimum Standards in Humanitarian Response. 2016. http://www.spherehandbook.org/ en/introduction-5/ (accessed 14 Dec 2016).

4. WHO. United Nations Interagency Task-Force on the Prevention and Control of Non-communicable Diseases. Non communicable diseases in emergencies. Geneva: World Health Organization, 2016. 